\title{
Anterior and Posterior Association Cortex Contributions to the Somatosensory P300
}

\author{
Shuhei Yamaguchi ${ }^{1,2}$ and Robert T. Knight ${ }^{1}$ \\ 'Department of Neurology, University of California at Davis, Veterans Administration Medical Center, Martinez, California, \\ 94553 and ${ }^{2}$ Third Division of Internal Medicine, Shimane Medical University, Izumo, 693 Japan
}

\begin{abstract}
A P300 (P3)-evoked response is generated in a variety of mammalian species upon detection of significant environmental events. The P3 component has been proposed to index a neural system involved in attention and memory capacity. We investigated the contribution of anterior and posterior association cortex to somatosensory P3 generation. Somatosensory event-related potentials (ERPs) were recorded in controls $(n=10)$ and patients with unilateral lesions in temporal-parietal junction $(n=8)$, lateral parietal cortex $(n=8)$, or dorsolateral frontal cortex $(n=10)$. Subjects pressed a button to mechanical taps of the fifth finger (targets; $p=0.12$ ), randomly interposed in sequences of taps to the second (standards; $p=0.76$ ) and the third or fourth finger (tactile novels; $p=0.06$ ). Occasional shock stimuli were delivered to the wrist (shock novels; $p=0.06$ ).

The scalp-recorded P3 was differentially affected by anterior and posterior association cortex lesions. Subjects with temporal-parietal lesions showed markedly reduced P3s to all types of stimuli at all scalp locations. The reductions were largest at the parietal electrode site over the lesioned hemisphere. Parietal patients had normal P3s for all stimulus types except for contralateral shock novels, which generated reduced P3s. Frontal lesions had reductions of the novelty P3 over frontal sites with minimal changes in the target P3.
\end{abstract}

The data support the existence of multiple intracranial P3 sources. The data further indicate that association cortex in the temporal-parietal junction is critical for generating the scalp-recorded target and novelty P3s, whereas dorsolateral frontal cortex contributes preferentially to novelty P3 generation. The N2 component was reduced by parietal and frontal lesions in patients who had intact target P3s, suggesting that different neural systems underlie N2 and P3 generation.

Endogenous event-related potentials (ERPs) are time-locked electric fields generated by synchronous neural regions engaged in cognitive processing. ERPs have clarified the timing and ordering of stages of information processing and have provided

Received July 17, 1990; revised Jan. 29, 1991; accepted Feb. 4, 1991.

This work was supported by Javits Award NS21135 and by the Veterans Administration Research Service. Special thanks to Clay Clayworth for technical assistance in all phases of the project.

Correspondence should be addressed to Shuhei Yamaguchi, M.D., Department of Neurology, University of California at Davis, Veterans Administration Medical Center, 150 Muir Road, Martinez, CA 94553.

Copyright (C) 1991 Society for Neuroscience $0270-6474 / 91 / 112039-16 \$ 03.00 / 0$ insights into the neural basis of cognition in humans. The P300 (P3) component, first described in 1965 (Desmedt et al., 1965; Sutton et al., 1965), is a reliable ERP recorded in a variety of experimental paradigms. The P3 has been widely studied because of its association with psychological constructs including orientation, attention, stimulus evaluation, and memory. However, a generally accepted theory of the functional significance and neural generators of the P3 is lacking (Desmedt et al., 1979; Donchin, 1979).

Data from several areas of investigation have proposed P3 sources in limbic (Halgren et al., 1980; Okada et al., 1983; McCarthy et al., 1989), diencephalic (Yingling and Hosobuchi, 1984; Katayama et al., 1985; Velasco et al., 1986), and neocortical (Vaughan et al., 1983; Wood and McCarthy, 1985; Knight et al., 1989; Smith et al., 1990) regions. Limbic structures have received considerable attention as candidate $\mathrm{P} 3$ generators because large-amplitude, phase-reversing ERPs with latencies in the range of the simultaneously scalp-recorded P3 can be recorded from the human medial temporal structures (Halgren et al., 1980; Wood et al., 1980; Stapleton et al., 1987; McCarthy et al., 1989). However, unilateral anterior temporal lobectomy does not significantly reduce the P3 at midline scalp sites in humans (Wood et al., 1982; Johnson, 1988), and bilateral amygdalo-hippocampectomy does not reduce a monkey P3-like potential (Paller et al., 1988). Thus, the hippocampal contribution to the scalp P3 is uncertain.

Some of the controversy regarding the neural origin of the P3 may be due to the fact that multiple brain regions contribute to the scalp-recorded P3. For instance, at least two types of P3 are recorded in normal subjects in the visual (Courchesne et al., 1975; Beck et al., 1980), auditory (Squires et al., 1975; Knight, 1984), and somatosensory modalities (Yamaguchi and Knight, 1991). Task-relevant, correctly detected stimuli generate a parietal maximal P3 (target P3), whereas nontarget, deviant stimuli requiring no behavioral response generate an earlier latency, frontocentral P3 (novelty P3).

Lesions in the temporal-parietal junction result in comparable decrements in the auditory target and novelty P3 (Knight et al., 1989). Patients with similar temporal-parietal lesions have marked reductions of the visual novelty P3 comparable to that observed in the auditory modality. However, these same patients have lesser reductions of the visual target P3 (Knight, 1990). Prefrontal lesions are reported to produce larger decrements in the novelty $\mathbf{P} 3$ than in the target P3 in both the auditory and the visual modality (Knight, 1984, 1990; Scabini et al., 1989).

These data indicate that intra- and intermodality association 


\section{TEMPORAL-PARIETAL}

1

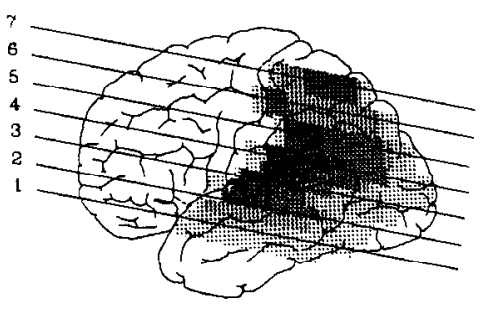

4

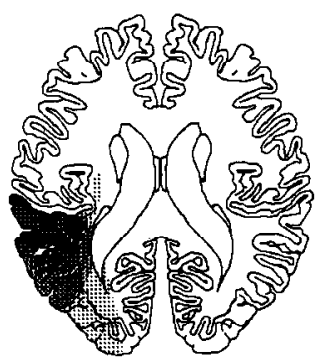

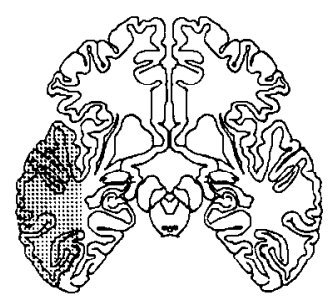

5

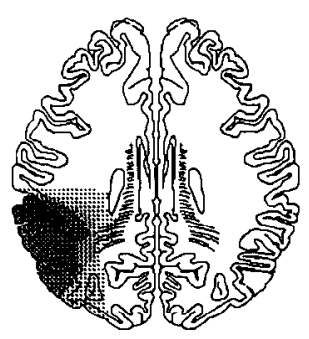

2

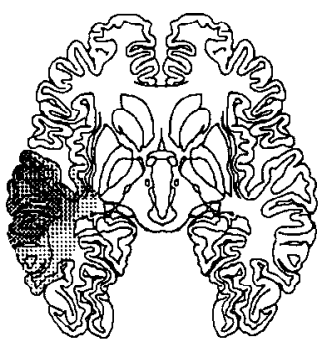

6

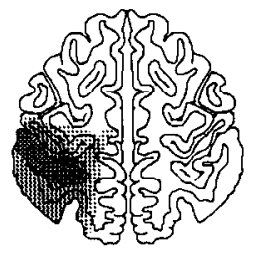

3

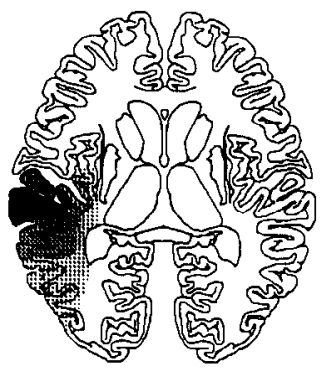

7

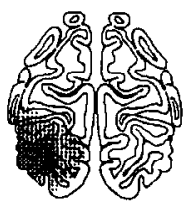

Figure 1. Lesion extent in patients with focal unilateral damage primarily in the temporal-parietal junction. The numbered lines on the lateral reconstruction (upper left) indicate the location of the axial sections (1-7) used in CT or magnetic resonance imaging (MRI) transcription. Lesions determined by CT scan from individual patients were transcribed onto templates $0^{\circ}$ to canthomeatal line. A lateral view of the lesion extent was then projected from the axial sections by software reconstruction methods. The digitized lesion data from individual subjects were then averaged to generate the group lesion densities for both lateral and axial views. Unilateral right-hemisphere lesions have been reflected onto the left hemisphere. Lesions were averaged over eight patients (4 left, 4 right; mean lesion volume, $67 \mathrm{cc}$ ). The shading scale indicates the percentage of patients with damage in the corresponding area.

cortex circuits are engaged during target and novelty P3 generation. We assessed somatosensory target and novelty $\mathrm{P} 3$ in patients with a focal brain lesion in subregions of anterior and posterior association cortex to provide further information on the neural systcms underlying scalp P3 generation.

\section{Materials and Methods}

Subjects. Controls and three patient groups were tested. The control group consisted of 10 right-handed subjects (mean age, $63 \pm 9 \mathrm{yr}$ ), matched in age and sex to the patients. They were recruited from hospital staff personnel and were healthy and without history of neurological or psychiatric diseases. Patients were selected on the basis of a unilateral focal lesion in either anterior or posterior association cortex. Lesions evident on CT scan were transcribed onto corresponding CT templates by two independent raters. Software permitted reconstruction of the lateral perspective, determination of lesion volume and cytoarchitectonic areas affected, and extraction of group-averaged lesions. Figures 1-3 show the average axial reconstructions and lateral views of the three patient groups.

Eight patients had lesions primarily involving lateral superior temporal gyrus, posterior superior temporal plane, and inferior portions of the supramarginal gyrus (temporal-parietal group; mean age, $63 \pm 8$ yr; 4 right, 4 left; mean lesion volume, $67 \pm 42 \mathrm{~cm}^{3}$; Table 1, Fig. 1). The second patient group consisted of eight patients with lesions primarily involving superior parietal lobule and superior portions of the supramarginal and angular gyri (parietal group; mean age, $60 \pm 11 \mathrm{yr}$; 4 right, 4 left; mean lesion volume, $27 \pm 14 \mathrm{~cm}^{3}$; Table 2, Fig. 2).
Although temporal-parietal and parietal groups had substantial overlaps in lesions, these groups were anatomically differentiated on the basis of involvement of lateral superior temporal gyrus, posterior superior temporal plane, and inferior portions of the supramarginal gyrus. The third group consisted of 10 patients with dorsolateral frontal lesions (frontal group; mean age, $66 \pm 8 \mathrm{yr} ; 5$ right, $5 \mathrm{left}$; mean lesion volume, $37 \pm$ $13 \mathrm{~cm}^{3}$; Table 3, Fig. 3).

All lesions were due to cerebral infarctions and were at least 1 yr postonset. Craniotomy patients were excluded to avoid possible effects on ERP scalp voltages of current shunting through bone defects. Patients with medical complications, psychiatric disturbances, substance abuse, or dementia were also excluded. Neurological examinations showed neither marked hemiparesis nor peripheral neuropathy.

Primary somatosensory sensation (pain, touch, vibration, and proprioception) was assessed in all subjects prior to the experiment. Two subjects (both with right lesions) in the temporal-parietal group and one subject (with right lesion) in the parietal group showed moderate disturbances in primary somatosensory sensation and could not perform the detection task correctly in the limb contralateral to the lesion. These three subjects had reduced somatosensory evoked potentials (SEPs). For these three subjects, ERP data only from the unaffected hand were used for analysis. All other subjects in the temporal-parietal and parietal groups and all subjects in the control and frontal groups could make correct discriminations with more than $60 \%$ accuracy (see Tables $1-3$ for details).

Experimental design. The somatosensory stimuli consisted of mechanical taps to the digits and electric shocks to the wrist. Mechanical taps were delivered separately to the second, third, fourth, and fifth fingertips with solenoids activated by a $50-\mathrm{msec}$-duration square-wave 


\section{PARIETAL}

1

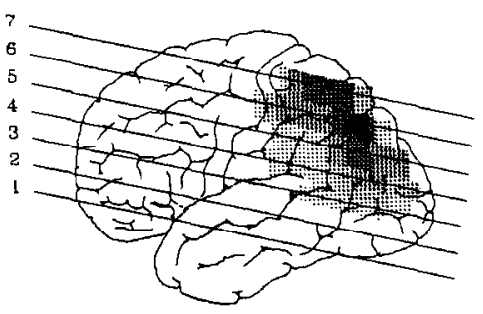

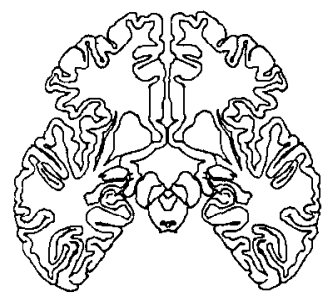

5

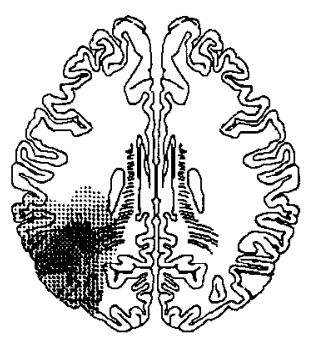

2

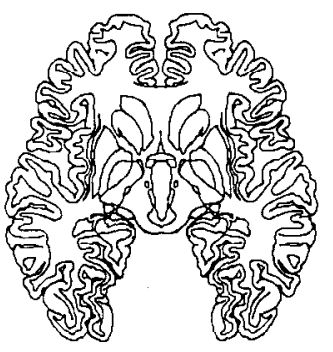

6

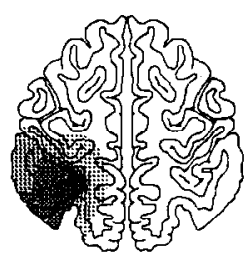

3

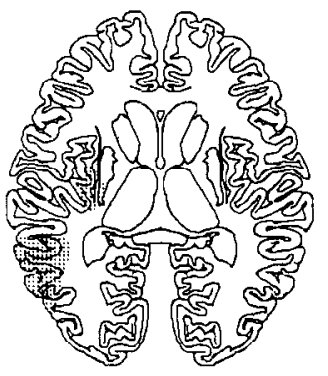

7

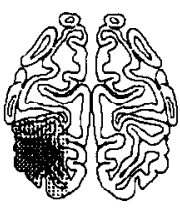

Figure 2. Averaged lesion extent in patients with lateral parietal lesions ( $n=8 ; 4$ left, 4 right; mean lesion volume, $27 \mathrm{cc}$; same format as Fig. 1).

electric pulse. All fingers were fixed in a hand brace, which limiled finger movement. For the shock stimuli, electrical square pulses of $0.2 \mathrm{msec}$ duration were delivered to the median nerve at the wrist by a stimulator (Grass Instrument Co.) through an isolating transformer. The intensity of the shock stimulation was in the range employed to produce an opponens pollicis twitch in conventional SEP recordings. The twitch threshold was determined by delivery of a few stimuli prior to ERP recording. There was no significant difference in intensity of delivered current to the right and left wrist among the four groups.

The experiment consisted of four blocks designed to produce replication of each wave form. Each block consisted of 500 stimuli delivered at a rate of $1 / \mathrm{sec}$. Of these stimuli, $76 \%$ were mechanical tactile stimuli to the second finger (standards), 12\% were mechanical tactile stimuli to the fifth finger (targets), $6 \%$ were mechanical tactile stimuli to the third or fourth finger (tactile novels), and 6\% were electric shock stimuli to the median nerve (shock novels). Target and novel stimuli were interspersed at random in the sequence. A previous study showed that occasional shock stimuli interposed in trains of tactile stimuli generated a prominent novelty $\mathrm{P} 3$ that was similar in latency and scalp topography to the novelty P3 reported in the auditory and visual modalities (Yamaguchi and Knight, 1991). Stimulus randomization and delivery were controlled by a PC computer. Two blocks (first and fourth block) were assigned to the one hand, and another two blocks (second and third block) were given to the other hand. The order of hand stimulation was counterbalanced across subjects.

The subject was seated in a reclining chair in a sound-attenuated chamber and was instructed to press a button with the thumb of the nonstimulated hand only upon detection of tactile stimuli to the fifth finger. The subject was instructed to press as accurately and quickly as possible and not to respond to any other stimuli. Two- or three-minute rest periods intervened between blocks. During the experiment, white noise ( $70 \mathrm{~dB} \mathrm{SPL})$ was presented through headphones to mask the sound produced by the solenoid. The subject was encouraged to minimize eye movements and blinks throughout the periods of stimulation.
Brain electrical activity was recorded using $\mathrm{Ag} / \mathrm{AgCl}$ electrodes placed at 15 scalp locations (Fpz, F3, Fz, F4, T3, C3, Cz, C4, T4, T5, P3, Pz, P4, T6, and $\mathrm{Oz}$ ) based on the 10-20 system and below the left eye, all referenced to linked earlobes. Electrode impedances were kept below 5 $\mathrm{K} \Omega$. The EEG was amplified (band pass, 0.1-100 cycles/sec), digitized $(250 \mathrm{~Hz} / \mathrm{channel})$, and stored on magnetic tape for off-line analysis by a PDP $11 / 73$ computer. The averaging epoch was $1024 \mathrm{msec}$, including $200 \mathrm{msec}$ of prestimulus baseline. Individual trials with excessive muscle activities (peak-to-peak amplitude, $80 \mu \mathrm{V}$ ) or eye blinks (peak-to-pcak amplitude, $100 \mu \mathrm{V}$ ) were excluded from the average. Because lesions had effects on exogenous, stimulus-dependent ERPs to the standard stimuli (i.e., P200) as described later, difference waves were derived by subtracting the ERP to standard stimuli from the ERP to target, tactile, and shock novel stimuli. This permitted extraction of endogenous, $\operatorname{cog}$ nitively related ERP components (i.e., N2, P3).

Data analysis. Peak amplitudes were measured relative to the 200 msec prestimulus baseline in the difference waves. Measurement windows were determined from inspection of individual subject averages and group superaverages. The P200 component was measured within a poststimulus window of $160-230$ msec in the ERPs for standard stimuli. The P3 component was defined as the most positive peak occurring in a window of 270-650 msec for all infrequent target and novel stimuli. The N2 component was measured within a window of $180-270 \mathrm{msec}$ for all infrequent stimuli. Peak latency of each component was also tabulated in these windows. Only data from correctly detected targets were included in the averages. Correct responses were defined as a reaction time (RT) between 150 and $1000 \mathrm{msec}$ after stimulus delivery.

The data were organized as a function of the stimulated hand contralateral or ipsilateral to lesion and as a function of electrode site over lesioned (i.e., Pi, Fi, Ti, Ci, pTi) or nonlesioned (i.e., Pc, Fc, Tc, Cc, $p \mathrm{Tc}$ ) hcmisphcre. The scalp voltages were then subjected to repeatedmeasures analysis of variance. Because scalp recordings do not provide independent measures, amplitude changes were considered significant only if seen at single electrode sites. In the control group, there was no 


\section{FRONTAL}
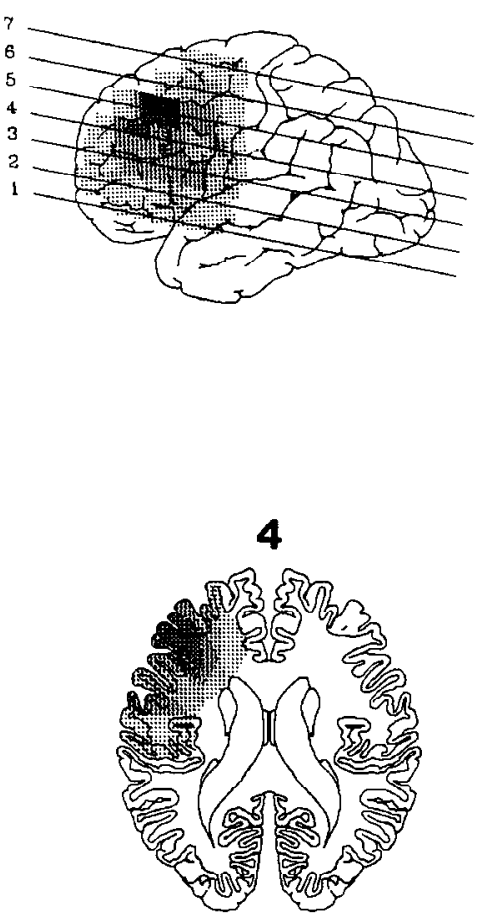

1
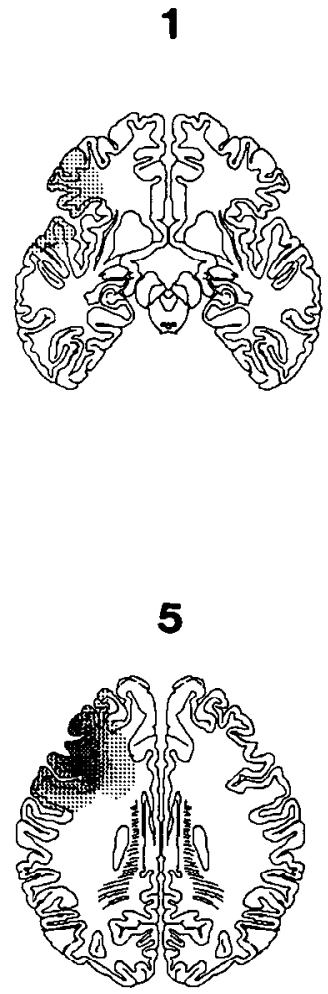

2

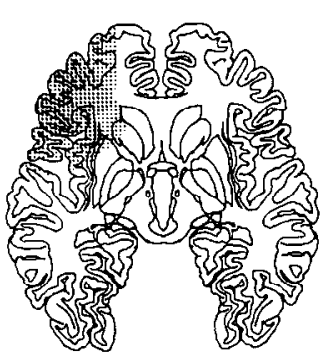

6

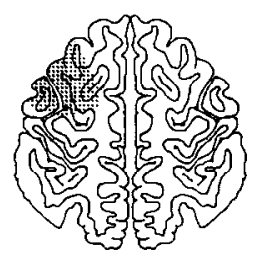

3

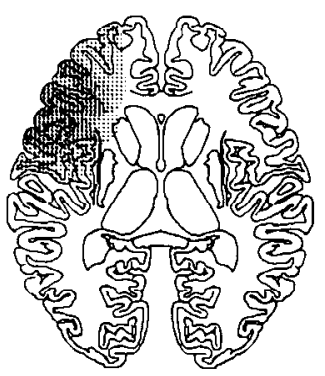

7

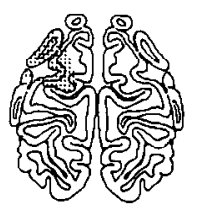

Figure 3. Averaged lesion extent in patients with frontal lesions ( $n=10 ; 5$ left, 5 right; mean lesion volume, $37 \mathrm{cc}$; same format as Fig. 1$)$.

difference in ERP wave shapes between right- and left-hand stimulation, and ERPs were averaged across four blocks. The control data are shown with the stimulated hand on the same side as the side of stimulation in the patient group.

$S E P S$. After ERP recording, conventional SEPs were recorded to assess the intactness of primary somatosensory cortex. Three-hertz electric stimulation sufficient to induce a thumb twitch was applied to the median nerve at the wrist. Electrodes and references were the same as for the ERP study. Amplifier band pass was set at $10-1000 \mathrm{~Hz}$, and a 331msec epoch was digitized on line to magnetic tape at a sampling rate of 769 points/sec. Trials with excess EMG interference were automatically cxcluded from the average. A total of 500 rcsponscs wcrc avcraged with replications of an additional 500 responses for each hand of stimulation in a counterbalanced design.

Two components (N20 and P27) were measured at the parietal electrode contralateral to the hand of stimulation. These components represent the neural activity at the primary somatosensory cortex (N20 from area 3b and P27 from area 1 or 2; Sutherling et al., 1988; Allison et al., 1989; Yamaguchi and Knight, 1990). Peak amplitudes were measured relative to the 20 -msec prestimulus baseline activity with a window of 17-23 msec for the N20 and 24-33 msec for the P27. Peak latency was tabulated relative to stimulus delivery in these windows.

\section{Results}

Behavioral

Temporal-parietal and frontal groups showed decreased detection accuracies for targets delivered contralateral to the lesion (percent correct detection; controls: $98.0 \pm 1.5 \%$; temporalparietal: $83.2 \pm 11.4 \%, p<0.001$; frontal: $87.8 \pm 9.8 \%, p<$ $0.01)$. The parietal group performed comparably to controls (parietal, $95.0 \pm 7.2 \%, p=\mathrm{NS}$ ). For stimulation ipsilateral to the lesion, detection accuracy was reduced only in the frontal group (frontal, $86.9 \pm 15.4 \%, p<0.05$ ). Controls and the tem- poral-parietal and parietal groups performed comparably for ipsilateral stimuli (temporal-parietal, $91.9 \pm 10.3 \%$; parietal, $96.2 \pm 4.3 \% ; p-\mathrm{NS}$ ). False alarm rates were not significantly different among the four groups (control: $2.6 \pm 1.9 \%$; temporalparietal: contralateral, $15.1 \pm 19.4 \%$; ipsilateral, $11.7 \pm 17.0 \%$; parietal: contralateral, $2.8 \pm 3.8 \%$; ipsilateral, $3.7 \pm 4.6 \%$; frontal: contralateral, $6.2 \pm 6.5 \%$; ipsilateral, $8.5 \pm 9.2 \%$ ).

RTs were prolonged in all patient groups compared with controls for stimulation contralateral to the lesion (controls: $437 \pm$ $57 \mathrm{msec}$; temporal-parietal: $557 \pm 42 \mathrm{msec}, p<0.001$; parietal: $535 \pm 78 \mathrm{msec}, p<0.01$; frontal: $523 \pm 47 \mathrm{msec}, p<0.01$ ). There was no difference in RTs between the patient groups. For stimulation ipsilateral to the lesion, all patient groups again had significantly delayed RTs compared with controls (controls: 437 $\pm 57 \mathrm{msec}$; temporal-parietal: $556 \pm 81 \mathrm{msec}, p<0.005$; parietal: $524 \pm 92 \mathrm{msec}, p<0.05$; frontal: $505 \pm 49 \mathrm{msec}, p$ $<0.001$ ). However, RTs again did not differ between the patient groups. RTs for contralateral stimulation were prolonged relative to ipsilateral stimulation, but the differences did not reach significance in any patient group.

RTs were inversely correlated with correct detection rate in the temporal-parietal and parietal groups (temporal-parietal: $r$ $=-0.63, p<0.05$; parietal: $r=-0.77, p<0.01)$ and showed a trend of inverse correlation in the control and frontal groups (control: $r=-0.59, p<0.1$; frontal: $r=-0.38, p<0.1$ ).

\section{Electrophysiological P200 component}

The standard stimuli generated little or no P3 and thus allow examination of P200 uncontaminated by P3 (Fig. 4). The control 


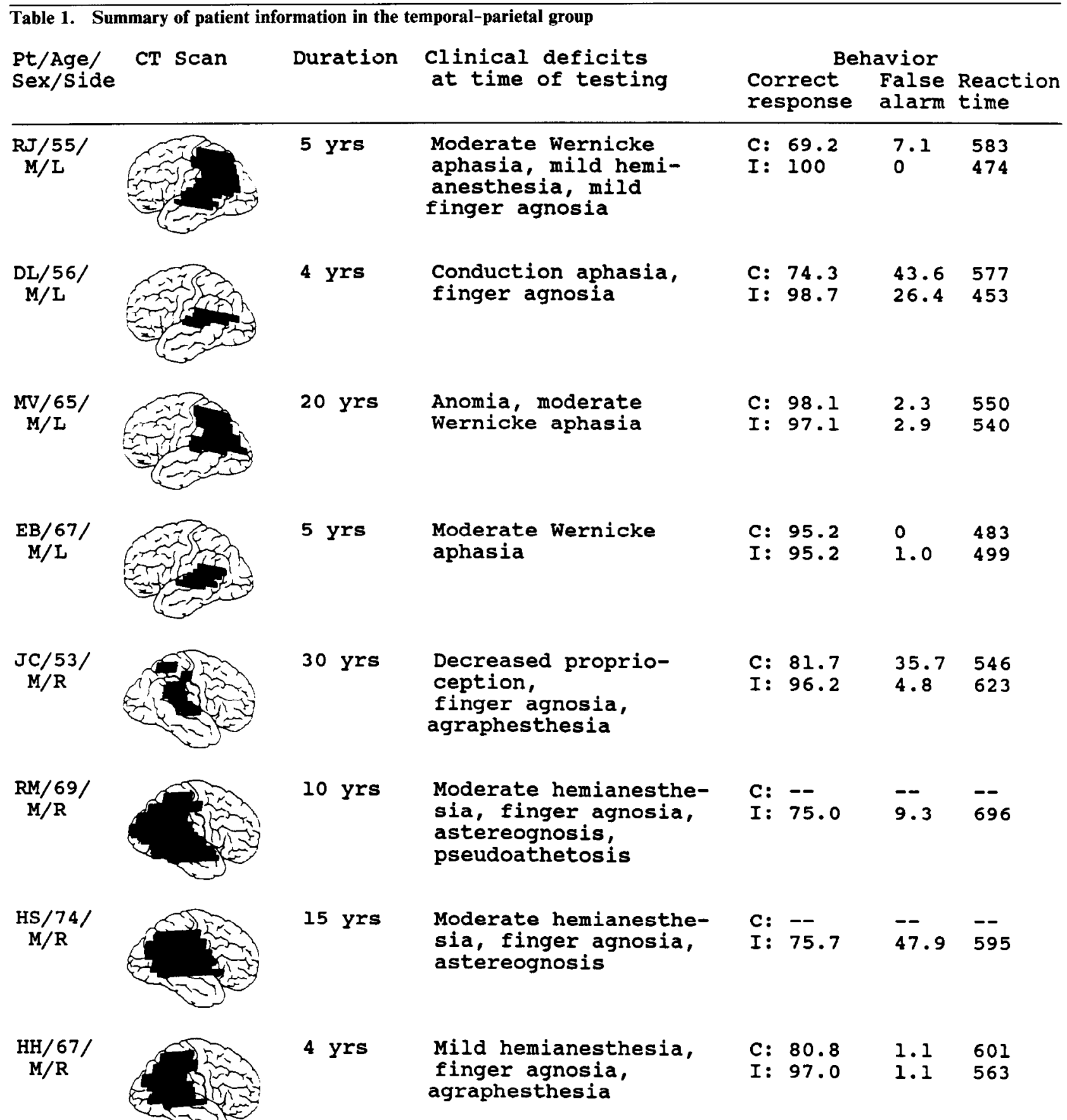

group generated a frontocentral maximal P200 component to standard stimuli (latency, $202 \pm 32 \mathrm{msec}$ ). The temporal-parietal group had a reduced $\mathrm{P} 200$ amplitude (contralateral stimuli: $65 \%$ reduction at $\mathrm{Cz}, F_{1,14}=15.6, p<0.01$; ipsilateral stimuli: $47 \%$ reduction at $\mathrm{Cz}, F_{1,16}=10.1, p<0.01$ ). Parietal lesions did not affect the P200. Frontal lesions also had reduced P200 amplitudes in comparison to the control group (contralateral stimuli: $58 \%$ reduction at $\mathrm{Cz}, F_{1,18}=18.7, p<0.001$; ipsilateral stimuli: $42 \%$ reduction at $\mathrm{Cz}, F_{1,18}=10.4, p<0.01$ ). Latency was unaffected in any lesion groups (at Cz: temporalparietal, $191 \pm 25 \mathrm{msec}$; parietal, $197 \pm 27 \mathrm{msec}$; frontal, 182 $\pm 22 \mathrm{msec}$; all $p=$ NS vs controls).
N2 and P3 components

\section{Control group}

Controls generated a parietal maximal target P3 (latency, 396 $\mathrm{msec}$ ) and a frontocentral maximal novelty P3 (latency for tactile novels, $417 \mathrm{msec}$; for shock novels, $352 \mathrm{msec}$; see Fig. 5). The target P3 had an asymmetrical scalp distribution at frontocentral scalp site. The novelty P3 had a symmetrical scalp distribution.

An N2 was observed prior to the P3. This component was maximal at central sites and symmetrical over both hemispheres for all infrequent stimuli (latency for targets, $205 \mathrm{msec}$; for tactile 


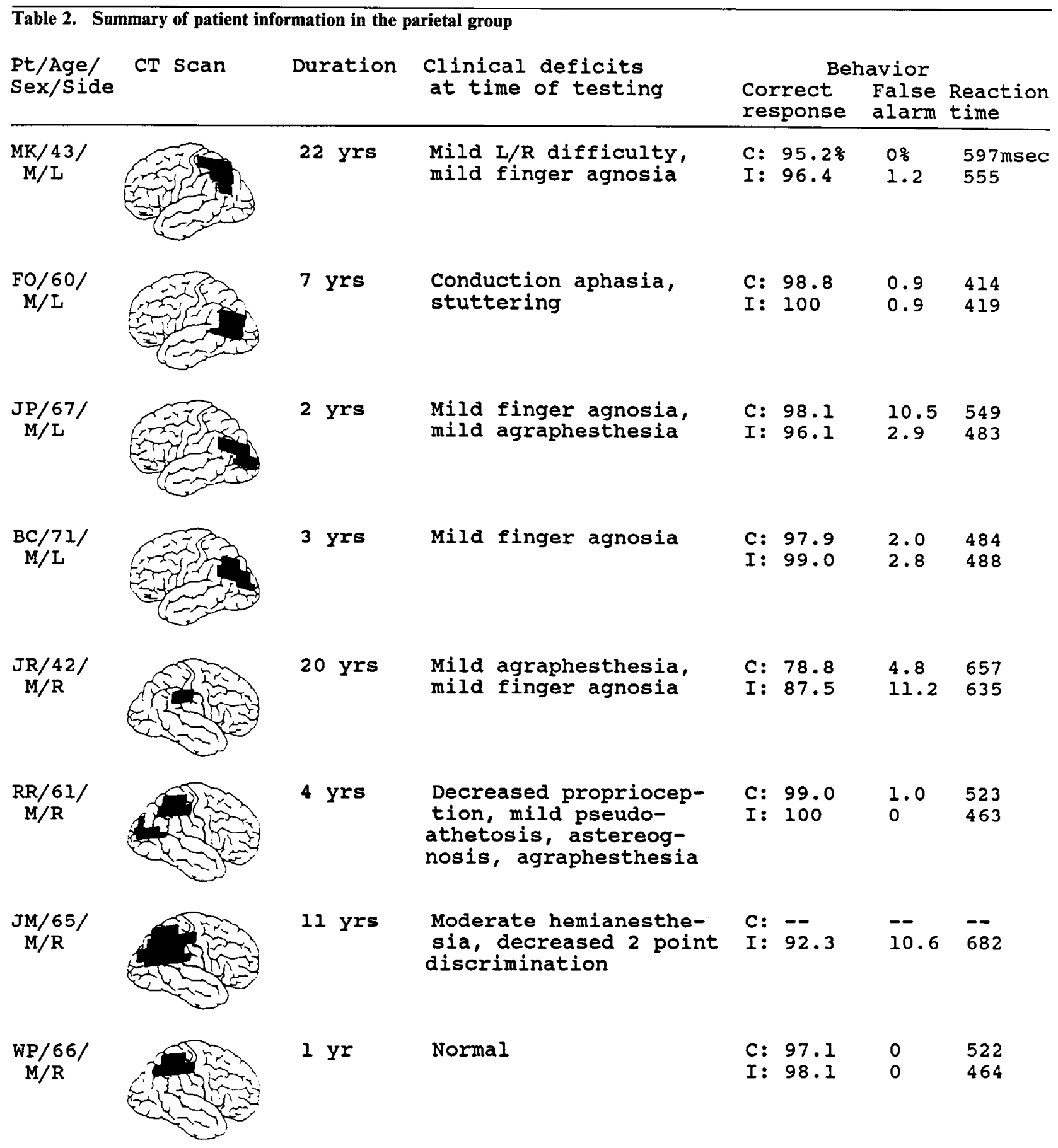

novels, $216 \mathrm{msec}$; for shock novels, $207 \mathrm{msec}$ ). Shock novel stimuli generated additional symmetrical frontocentral P100 and $\mathrm{N} 145$ components prior to the $\mathrm{N} 2$.

$\mathrm{N} 2$ and P3 latencies were correlated with RTs (N2 latency vs RT: $r=0.45, p<0.05$; P3 latency vs RT: $r=0.65, p<$ $0.01)$. Amplitude was not correlated with RTs. Correct response rates were not related to $\mathrm{N} 2$ and $\mathrm{P} 3$ measures.

\section{Temporal-parietal group}

Temporal-parietal lesions markedly reduced the P3 over the lesioned hemisphere to both target and novel stimuli delivered to the hand contralateral to the lesion (targets: $88 \%$ reduction at $\mathrm{Pi}, F_{1,14}=54.3, p<0.001$; tactile novels: $99 \%$ reduction at $\mathrm{Pi}, F_{1,14}=30.5, p<0.001$; shock novels: $91 \%$ reduction at $\mathrm{Pi}$, $F_{1,14}=80.5, p<0.001$; see Fig. 5). P3s were also reduced over the nonlesioned hemisphere (targets: $79 \%$ reduction at $\mathrm{Pc}, F_{1,14}$ $=26.1, p<0.001$; tactile novels: $78 \%$ reduction at $\mathrm{Pc}, F_{1,14}=$ $14.4, p<0.01$; shock novels: $85 \%$ reduction at $\mathrm{Pc}, F_{1,14}=60.8$, $p<0.001$ ).

For ipsilateral stimulation, temporal-parietal lesions also resulted in P3 amplitude reductions for all types of infrequent stimuli (targets: $67 \%$ reduction at $\mathrm{Pz}, F_{1,16}=22.3, p<0.005$; tactile novel: $86 \%$ reduction at $\mathrm{Cz}, F_{1.16}=16.0, p<0.001$; shock novels: $74 \%$ reduction at $\left.\mathrm{Cz}, F_{1,16}=17.3, p<0.001\right)$. The P3 


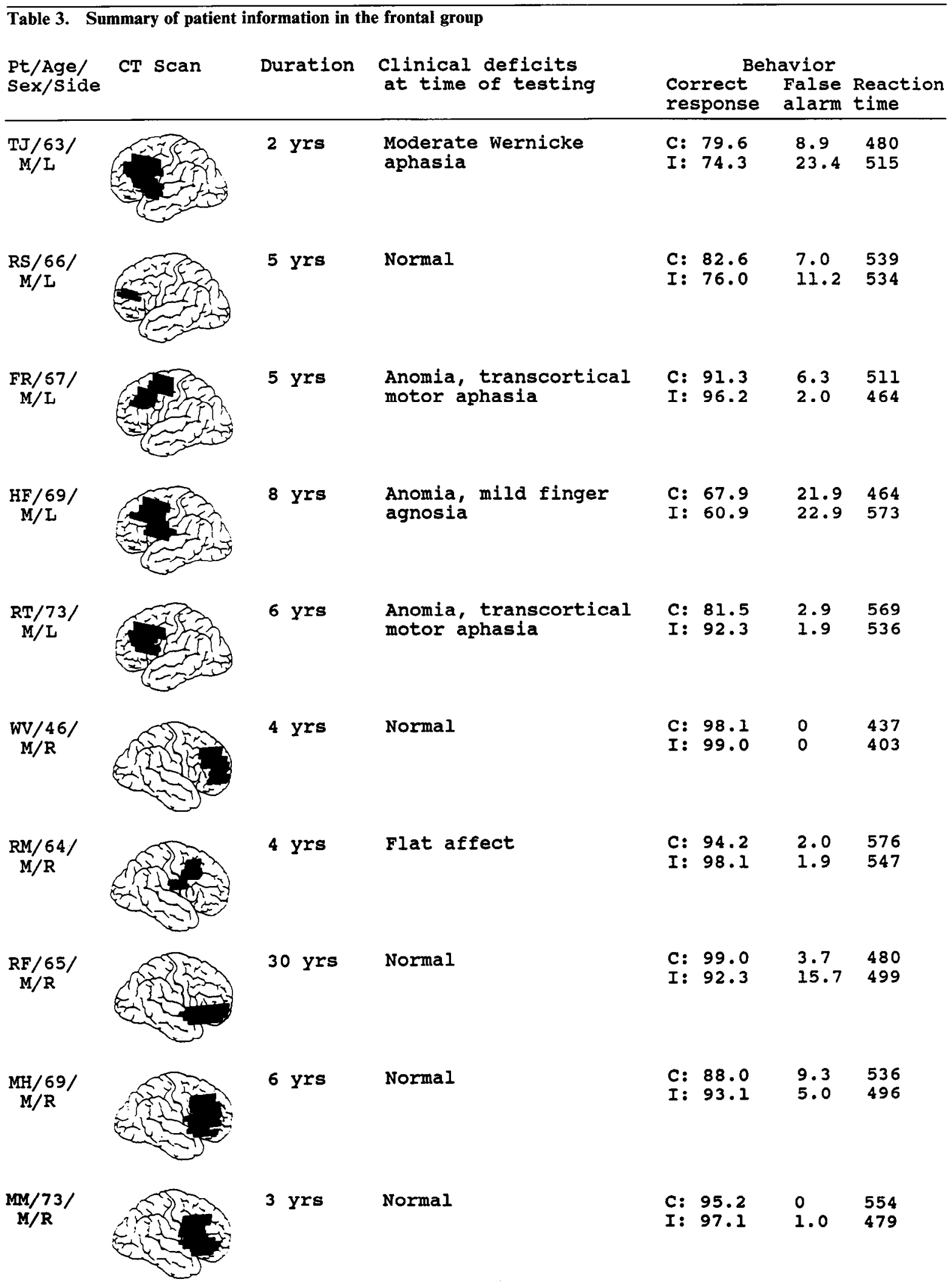

was reduced in each subject with a temporal-parietal lesion (see Fig. 6). P3 reductions were greater at the parietal site over the lesioned hemisphere in comparison with the nonlesioned hemisphere (Pi vs Pc; targets: $F_{1,7}=7.15, p<0.05$; tactile novels: $F_{1,7}=6.71, p<0.05$; shock novels: $F_{1,7}=10.9, p<0.05$; Figs.
$5,6)$. The P3 to ipsilateral shock stimuli was partially preserved at anterior scalp sites (Fig. 5).

Reliable P3 latencies were not obtainable for contralateral stimuli. P3 latencies were significantly prolonged for ipsilateral target and tactile novel stimuli compared with the control group 
CONTRALATERAL
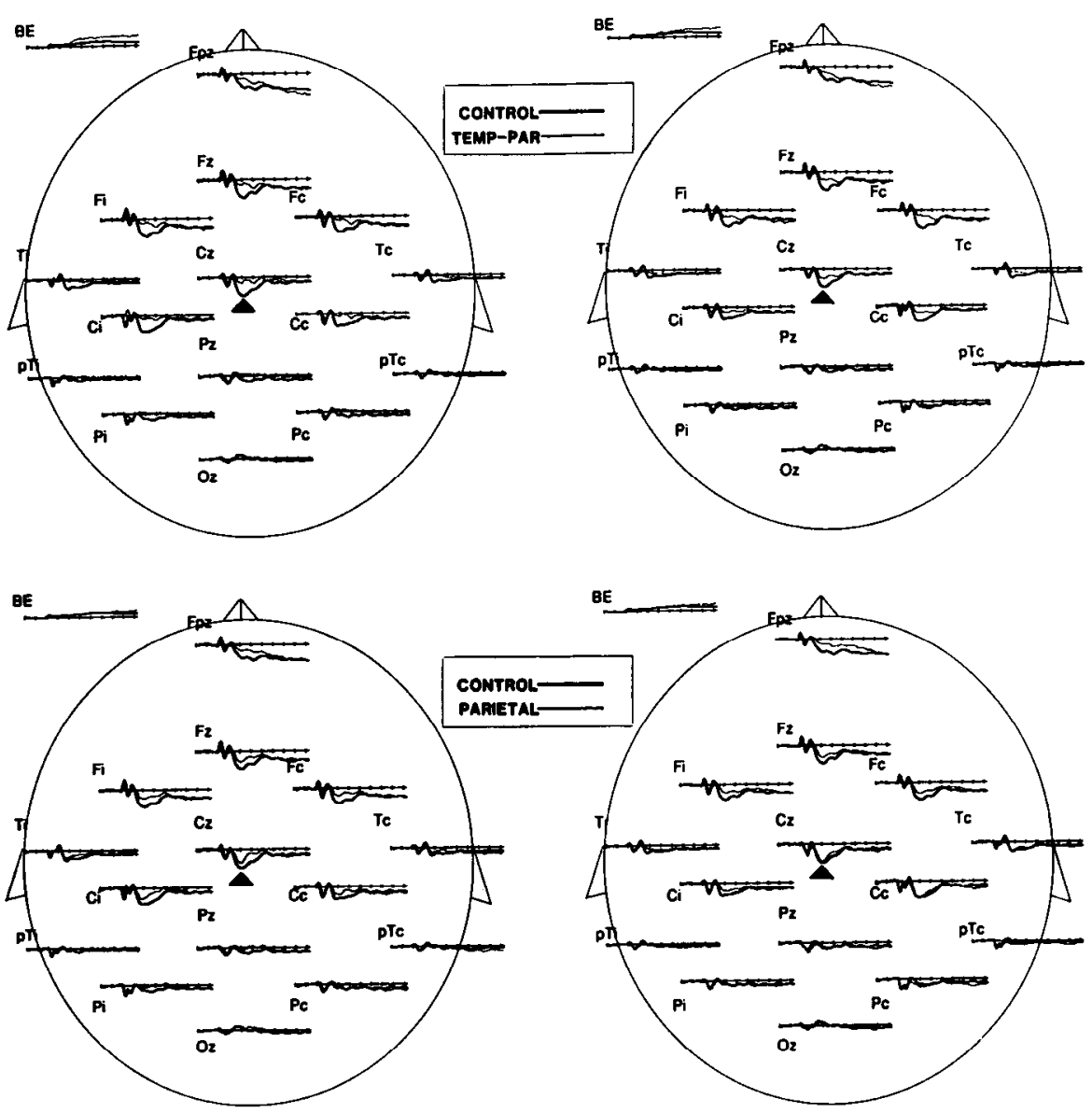

Figure 4. Grand average ERPs generated by standard stimuli to the hand contralatcral (left column) or ipsilatcral (right column) to the lesion for each patient group. The patient data are compared with the control group and are presented as a function of scalp sites ipsilateral (i.e., $P i, F i, T i, C i, p T i$ ) or contralateral (i.e., $P c, F c, T c, C c, p T c$ ) to the lesioned hemisphere. In the left column. data are shown as if the right hand were stimulated, and all lesions were in the left hemisphere. Solid triangles indicate the $\mathbf{P} 200$ component. $B E$, below eye; $T E M P-P A R$, temporalparietal.

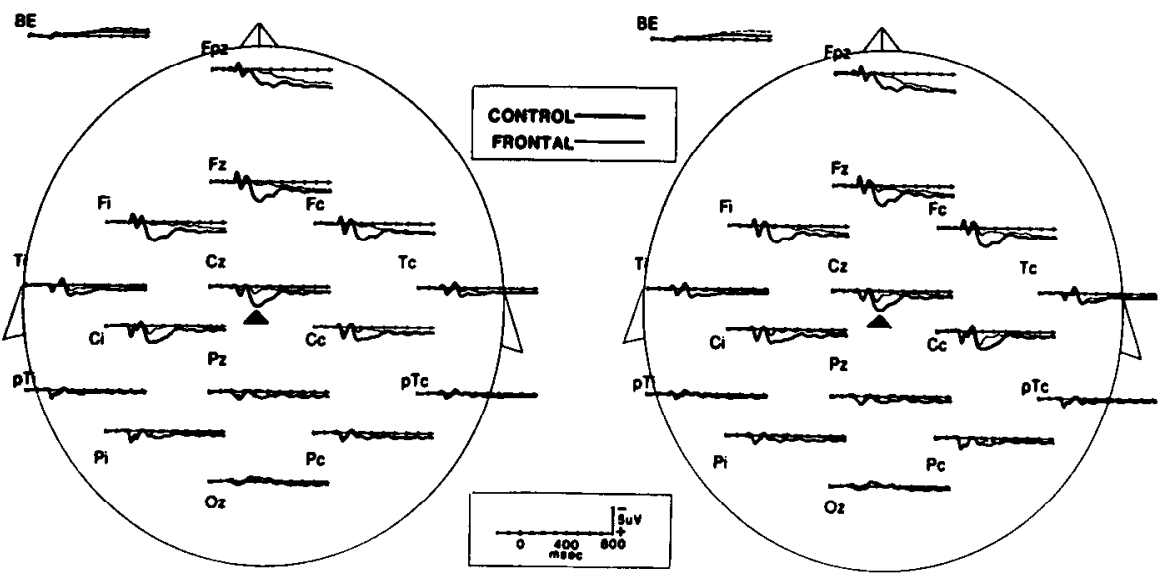

(targets, at Pz: $F_{1,16}=9.23, p<0.01$; tactile novels, at $\mathrm{Cz}: F_{1,16}$ $=22.6, p<0.001$ ) but not for shock novel stimuli.

The N2 amplitude was not different from the control group for target and tactile novel stimuli. The N2 component to contralateral shock stimuli was not decreased, though the N145 component was not clearly seen. The N2 component to ipsilateral shock novel stimuli was significantly reduced in amplitude $\left(46 \%\right.$ reduction at $\left.\mathrm{Cz} ; F_{1,16}=6.74 ; p<0.05\right)$, though latency was normal.

Correct response rates and RTs were not correlated with N2 and P3 measures.

\section{Parietal group}

The parietal group generated $\mathbf{P} 3$ components to target and tactile novel stimuli comparable to controls for stimulation both contralateral and ipsilateral to the lesion (Fig. 7). A nonsignificant reduction in target $\mathrm{P} 3$ amplitude was observed at the parietal electrode over the lesioned hemisphere. Shock novel stimuli delivered to the hand ipsilateral to the lesion also generated a normal P3. By contrast, the P3 evoked by shock novel stimuli delivered contralateral to the lesion was significantly reduced in amplitude over scalp sites in both hemispheres (vs. control: 
CONTRALATERAL

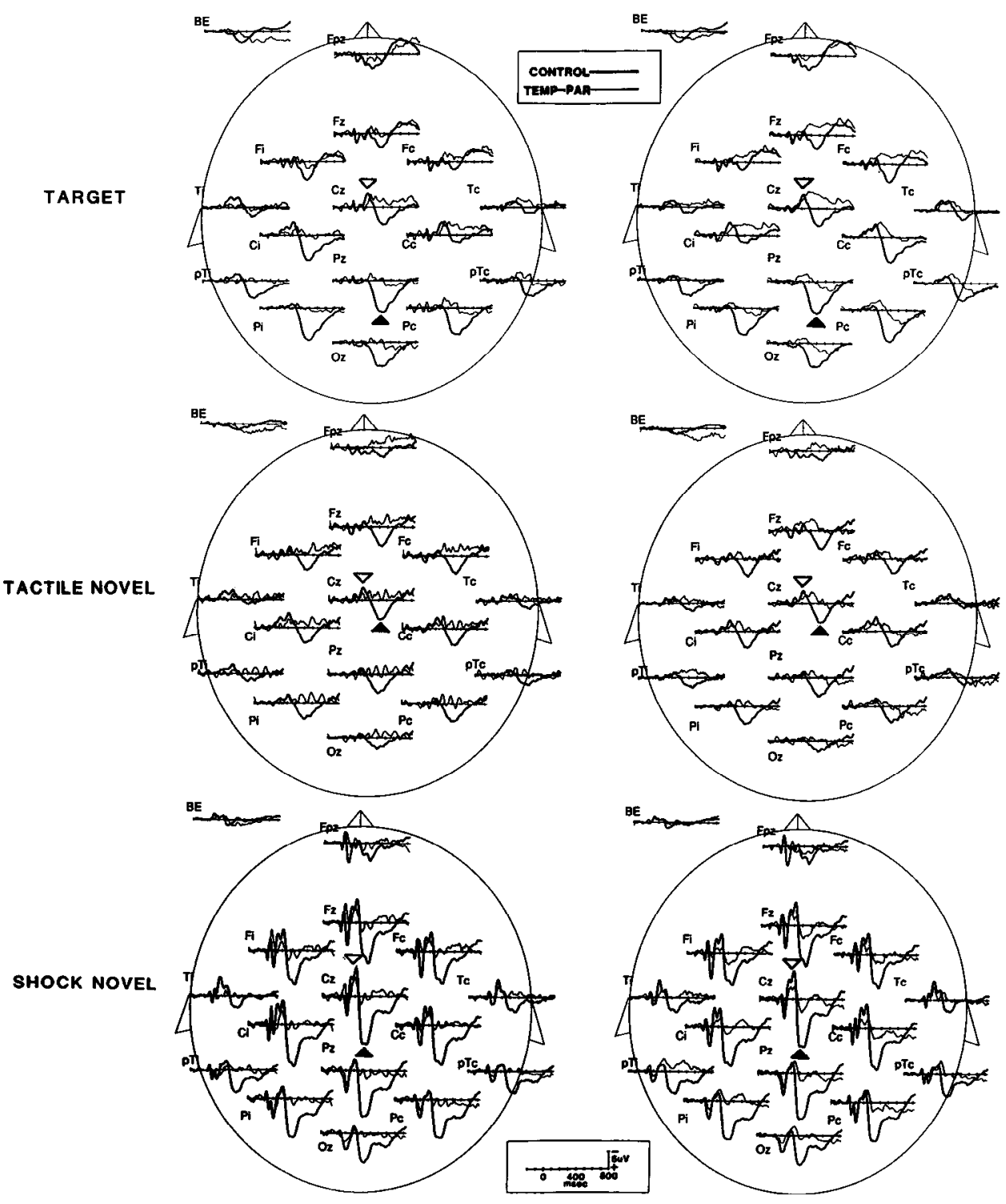

Figure 5. Grand average ERPs for temporal-parietal patients generated by target, tactile novel, and shock novel stimuli delivered to the hand contralateral or ipsilateral to the lesion (thin line). Data are compared with the control group (thick line). See Experimental design for stimulus parameters. Open and solid triangles indicate the $\mathrm{N} 2$ and P3 components, respectively. The patient data are organized as a function of electrodes ipsilateral or contralateral to the lesion. Abbreviations are as in Figure 4.
$33 \%$ reduction at $\mathrm{Cz}, F_{1,15}=5.52, p<0.05$ ). $\mathrm{P} 3$ latencies for all stimulus types were not affected by parietal lesions.

N2 amplitudes were significantly reduced for all types of contralateral infrequent stimuli in comparison with controls (at $\mathrm{Cz}$; targets: $64 \%$ reduction, $F_{1,15}=4.84, p<0.05$; tactile novels: $75 \%$ reduction, $F_{1,15}=6.15, p<0.05$; shock novcls: $89 \%$ rcduction, $\left.F_{1,15}=24.0, p<0.001\right)$. N2 amplitude for ipsilateral shock novel stimuli was also reduced $\left(64 \%\right.$ reduction at $\mathrm{Cz} ; F_{1,16}$ $=15.0 ; p<0.005$ ). $\mathrm{N} 2$ amplitude to ipsilateral target and tactile novel stimuli was not affected. N2 latencies were not affected by parietal lesions.

N2 and P3 latencies for contralateral target stimuli were correlated with $\mathrm{RTs}$ (N2 latency vs $\mathrm{RT}: r=0.75, p<0.01 ; \mathrm{P3}$ latency vs RT: $r=0.68, p<0.05$ ), whereas those for ipsilateral stimuli showed no correlations (N2, $r=0.09$; P3, $r=0.10$ ). Correct response rates did not correlate with N2 and P3 measures.

Because there was substantial lesion overlap between the pa- rietal and temporal-parietal group and the mean lesion volume was significantly larger in the temporal-parietal group $\left(F_{1,14}=\right.$ $6.86 ; p<0.05$ ), the relation between desion volume and $\mathrm{P} 3$ amplitude was examined. No significant correlation was observed between lesion volume and P3 amplitude for any infrequent stimuli (targets, $r-0.04$; tactile novels, $r=0.14$; shock novels, $r=0.05$ ). Furthermore, in subjects with the smallest temporal-parietal lesions (DL and EB; see Table 1), P3 was abolished for all types of infrequent stimuli (Fig. 8). Thus, the lesion effects on the P3 do not appear to be due to differences in lesion volume, but are related to damage in the lateral superior temporal gyrus, posterior superior temporal plane, and inferior portions of the supramarginal gyrus.

\section{Frontal group}

Frontal lesions had differential effects on target and novelty P3 (Fig. 9). Tactile and shock novelty P3 amplitudes were bilaterally reduced over frontal scalp sites for both contralateral and 


\section{CONTROL}

$\mathrm{Pi}$

TARGET
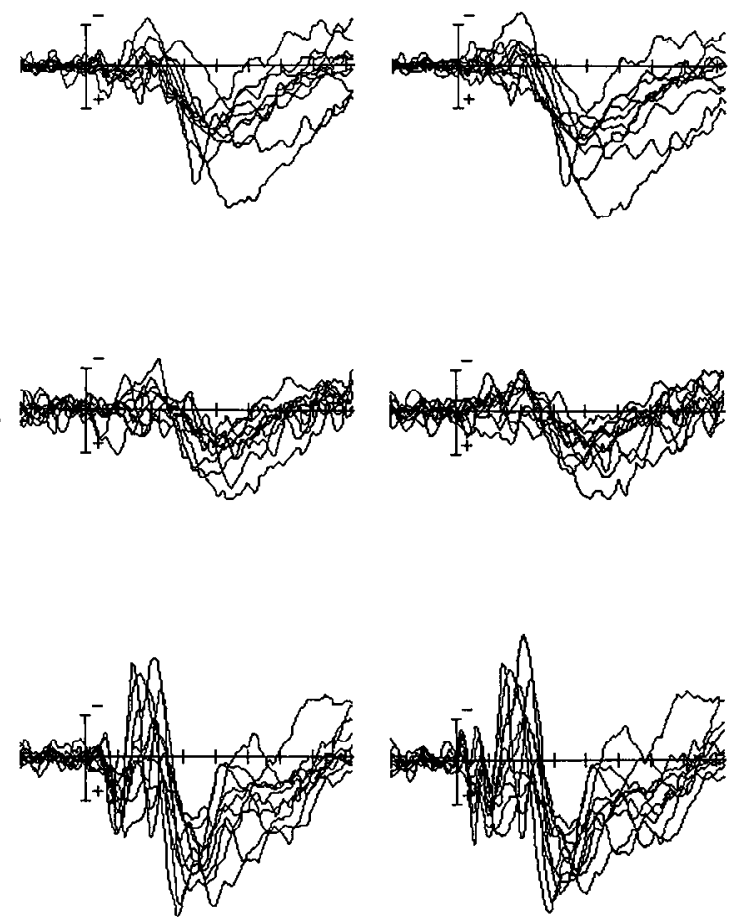

\section{TEMPORAL-PARIETAL}

$\mathrm{Pi}$
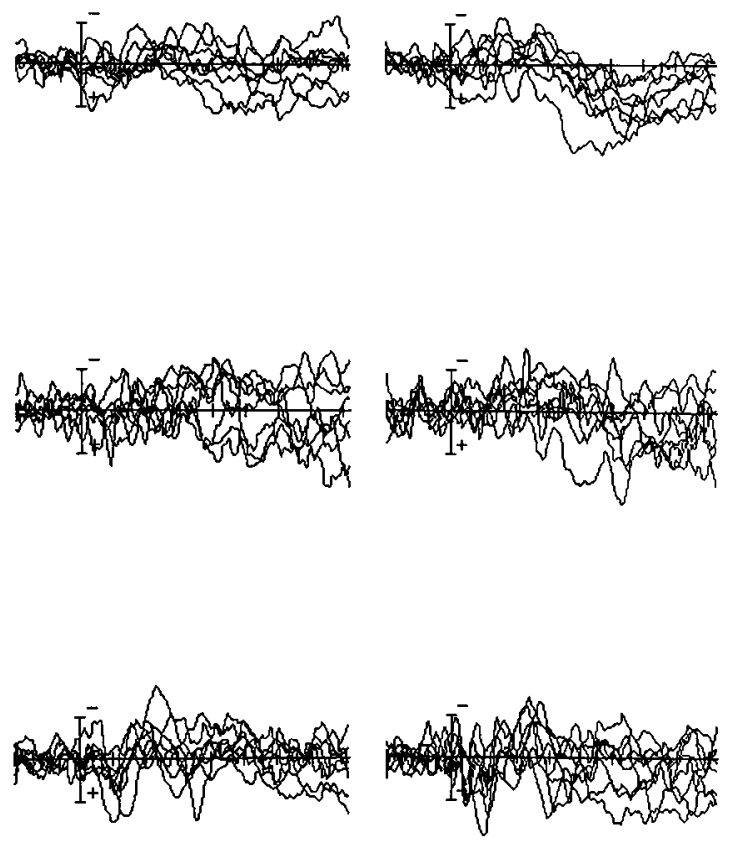

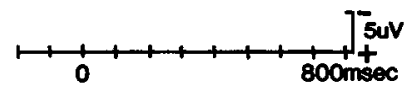

Figure 6. Superimposition of ERPs from individual subjects recorded at lateral parietal scalp sites in the control and temporal-parietal groups. In the temporal-parietal group, ERPs are shown for stimuli delivered to the hand ipsilateral to the lesion.

ipsilateral stimulation (at Fz; contralateral tactile novels: $65 \%$ reduction, $F_{1,18}=14.5, p<0.01$; contralateral shock novels: $58 \%$ reduction, $\mathrm{F}_{1,18}=13.2, p<0.01$; ipsilateral tactile novels: $53 \%$ reduction, $F_{1,18}=8.35, p<0.05$; ipsilateral shock novels: $49 \%$ reduction, $F_{1,18}=7.51, p<0.05$ ). There was no significant difference in novelty $\mathrm{P} 3$ reduction between lateral frontal electrode sites (Fi vs Fc for contralateral shock novels, $F_{1,9}=1.56$, NS). The frontal reduction in the novelty P3 amplitude was significantly larger than that seen at parietal sites $(\mathrm{Fz} / \mathrm{Pz}$ ratio; tactile novels: control, 1.32 ; frontal, $0.73 ; F_{1.18}=6.22 ; p<0.05$; shock novels: control, 1.10 ; frontal, $0.72 ; F_{1,18}=4.91 ; p<0.05$ ). Novelty $\mathrm{P} 3$ reductions were greater than target $\mathrm{P} 3$ reductions at frontal sites (target $P 3$ reduction of $37 \%$ vs tactile novels rcduction of $67 \%: F_{1,9}=9.00, p<0.05$; vs shock novels reduction of $\left.60 \%: F_{1,9}=6.10, p<0.05\right)$. Novelty P3 amplitude for contralateral shock stimuli was more reduced than ipsilateral stimuli, but the difference did not reach significance. The target P3 was reduced over the lesioned hemisphere only for contralateral stimulation (47\% reduction at Fi: $F_{1,18}=6.05 ; p<0.05$ ). There was no significant P3 latency delay for any types of infrequent stimuli.

Frontal lesions reduced $\mathrm{N} 2$ amplitude for all types of infrequent stimuli delivered to the contralateral hand (at $\mathrm{Cz}$; targets: $64 \%$ reduction, $F_{1,18}=6.06, p<0.05$; tactile novels: $67 \%$ re- duction, $F_{1,18}=7.96, p<0.05$; shock novels: $75 \%$ reduction, $F_{1,18}=15.5, p<0.001$ ). N2 amplitude was also reduced for ipsilateral shock novel stimuli $\left(82 \%\right.$ reduction at $\mathrm{Cz}: F_{1,18}=$ $28.5 ; p<0.001)$ and showed a trend toward reduction for ipsilateral target and tactile novel stimuli (at $\mathrm{Cz}$; targets: $49 \%$ reduction, $F_{1,18}=3.57, p<0.1$; tactile novels: $59 \%$ reduction, $F_{1.18}=3.88, p<0.1$ ).

The target P3 latency and amplitude for contralateral stimuli were correlated with RTs (P3 latency vs RT: $r=0.47, p<0.05$; P3 amplitude vs RT: $r=-0.46, p<0.05$ ), whereas those for ipsilateral stimuli showed no correlations. N2 latency and amplitude did not correlate with RTs. Correct response rates were also not correlated with $\mathrm{N} 2$ and P3 measures.

\section{SEPS}

After exclusion of three patients with primary somatosensory loss, all patient groups had N20 components comparable to the control group recorded over both lesioned and nonlesioned hemisphere (Fig. 10). The P27 amplitude was not affected by temporal-parietal and parietal lesion. However, the frontal group had an enhanced amplitude of the P27 component with delayed latency for stimulation contralateral to the lesion (amplitude: $64 \%$ increase, $F_{1.18}=4.70, p<0.05$; latency: $F_{1.18}=8.61, p<$ 


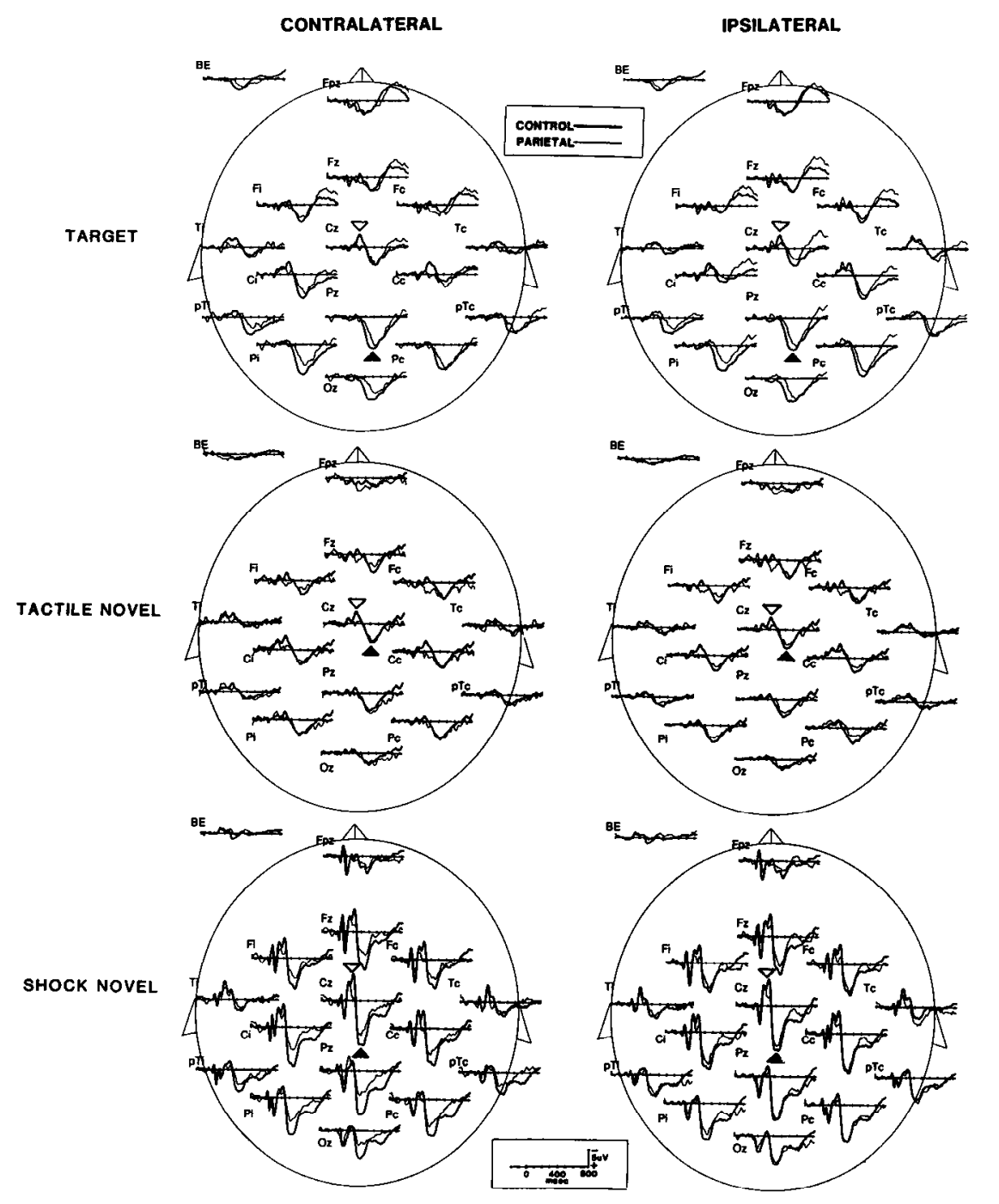

Figure 7. Grand average ERPs for parietal patients generated by target, tactile novel, and shock novel stimuli delivered ipsilateral and contralateral to the lesion (same format as Fig. 5).
0.01; Fig. 10). P27 amplitude was normal for stimulation ipsilateral to the frontal lesion.

\section{Discussion}

\section{Temporal-parietal lesions}

Unilateral temporal-parietal junction lesions markedly reduced P3 responses to all types of infrequent stimuli delivered either ipsilateral or contralateral to damage, supporting the notion that this region plays a critical role in scalp P3 generation. It is unlikely that the $\mathbf{P} 3$ reductions are due solely to deficits in stimulus discriminability because the averaged ERP for target stimuli was obtained from correctly detected events, group mean detection accuracy was above $80 \%$, and P3 was reduced for stimuli delivered to the limb ipsilateral to the lesion with normal detection capacity. RTs also did not vary between patient groups with and without P3. These results indicate that the neural systems involved in somatosensory discrimination may be distinct from those necessary for P3 generation.

Several possibilities arise regarding the bilateral reduction of the P3 by unilateral lesions. In a previous auditory study, five of six temporal-parietal patients studied had lesions in the dominant (left) hemisphere. Thus, a hemispheric asymmetry for $\mathbf{P} 3$ generation could not be ruled out (Knight et al., 1989). The present somatosensory study found equivalent $\mathrm{P} 3$ reductions in left $(n=4)$ and right $(n=4)$ temporal-parietal patients. Thus, an asymmetrically organized neural system for $\mathrm{P} 3$ generation is unlikely. Second, scalp-recorded P3 may be generated by subcortical midline structures dependent on bilateral hemispheric input. Diencephalic structures including thalamus, septal basal forebrain, and locus coeruleus have been proposed as candidate P3 generators or modulators (Yingling and Hosobuchi, 1984; Velasco et al., 1986; Harrison et al., 1988; Pineda et al., 1989). Although a subcortical midline generator does not easily explain the asymmetrical amplitude reduction of the P3 observed in some conditions in the temporal-parietal and frontal patients, abnormal cortical input to the structures off the midline, such as the amygdala and hippocampus, or to midline structures with laterally oriented dipoles could contribute to the asymmetric amplitude reductions recorded on the scalp. Third, interhemispheric integration of environmental information in the temporal-parietal junction may be necessary for $\mathrm{P} 3$ generation. In either of these explanations, it should be noted that an isolated temporal-parietal junction cannot function as the sole generator of the P3, but must also provide modulatory input to generators in either distant subcortical or cortical sites.

The data from the brain-damaged subjects provide some sup- 
Figure 8. Grand average ERPs in two TARGET
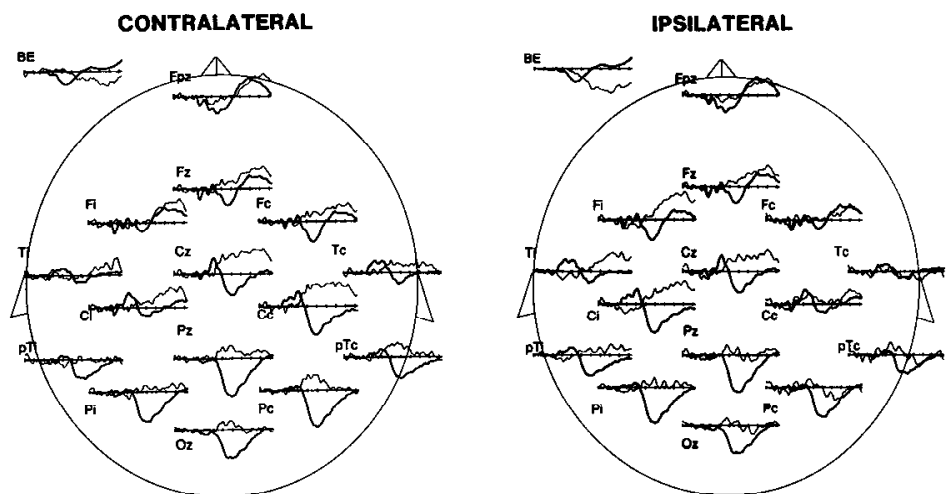

SHOCK NOVEL
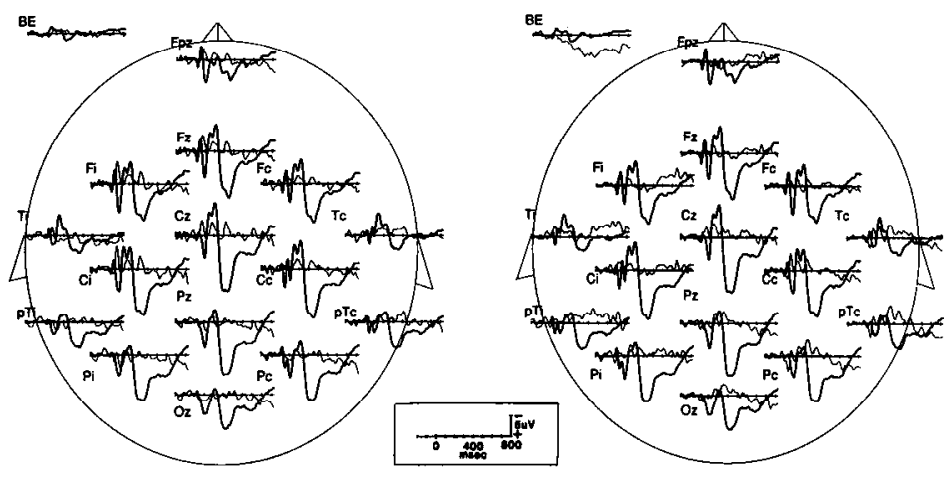

smallest lesion centered in the posterior superior temporal gyrus (same format as Fig. 5). The drawing at bottom shows lesion extent in two patients.
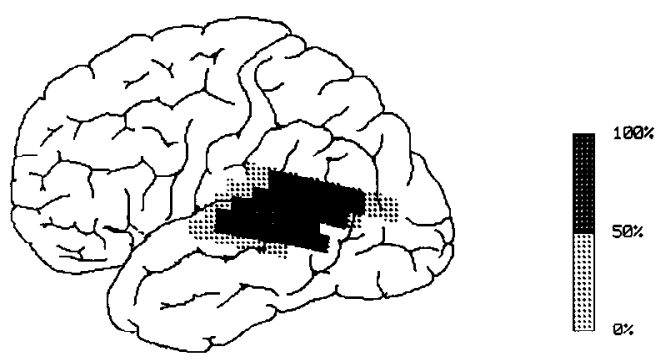

port for the third hypothesis. Stimuli delivered contralateral to the lesion resulted in bilateral $\mathbf{P} 3$ reduction. This could be explained by loss of a generator in the lesioned temporal-parietal junction and dysfunction of the unlesioned temporal-parietal generator due to loss of facilitatory input from the lesioned side. The P3 was reduced over the lesioned hemisphere when stimuli were delivered ipsilateral to the lesion, though some $\mathrm{P} 3$ activities could be recorded over the intact hemisphere in some conditions. This could be modeled by $\mathrm{P} 3$ generation in the intact temporal-parietal junction receiving the lateralized sensory information and loss of activity in the contralateral lesioned temporal-parietal junction (Scherg and Von Cramon, 1986). A report of intact $\mathrm{P} 3$ responses in callosotomy patients indicates that this putative interhemispheric effect may not be dependent on callosal pathways (Kutas et al., 1990).

Primate studies have documented that the inferior parietal lobule and superior temporal sulcus (STS) have reciprocal connections with frontal cortex, limbic structures, and reticular structures. Interaction between these regions and posterior association cortex may be necessary for sustaining a sensory tcmplate of the extrapersonal world and for directing attention towards behaviorally relevant sensory events (Mesulam, 1983). These regions appear to function both inter- and intrahemi- spherically and have substantial anatomical connections with ipsilateral and contralateral structures (Mesulam et al., 1977; Goldman-Rakic and Schwartz, 1982; Andersen et al., 1985; Scltzcr and Murphy, 1989).

Studies using single-unit recording have revealed specific neurons in area CSTP of the caudal STS whose neurons respond to polymodal sensory stimuli and have large receptive fields. These units have been proposed to index global attention to the external world (Hikosaka et al., 1988). Neuropsychological studies in humans have also described profound hemi-inattention or hemi-neglect syndromes from acute lesions in the temporalparietal junction, particularly evident after right hemisphere damage (Heilman et al., 1987).

The temporal-parietal junction in humans may correspond to multimodal area cSTP and auditory association area Tpt in the monkey. These regions have bidirectional connections to area TH in the parahippocampal gyrus. A network involving area $\mathrm{Tpt}$ and medial temporal structures has been proposed to be necessary for learning and memory in animals and humans (Amaral et al., 1983).

Studies in normals suggest that P3 amplitude predicts subsequent memory performance (Fabiani et al., 1986; Neville et al., 1986; Paller et al., 1987). A subset of the frontal and tem- 


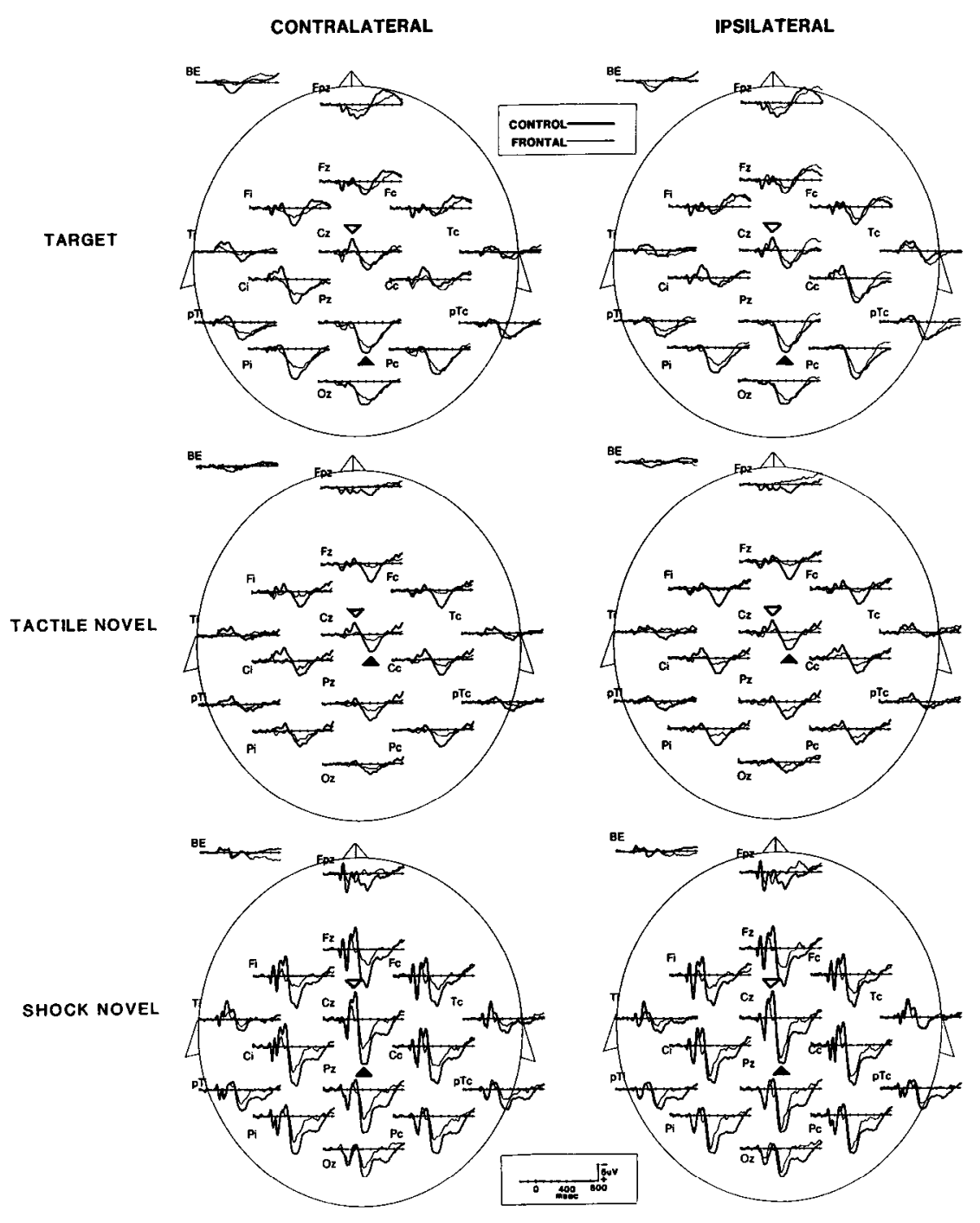

Figure 9. Grand average ERPs for frontal patients generated by target, tactile novel, and shock novel stimuli (same format as Fig. 5). poral-parietal subjects from the present study were found to have memory deficits manifested by differential problems in short- and long-term priming (Kersteen-Tucker and Knight, 1989). Taken together, these results suggest that the $P 3$ response is dependent on an association cortex and limbic system involved in sustaining and updating a model of the external environment (Donchin, 1979; Fabiani et al., 1986; Tulving and Schacter, 1990).

\section{Parietal lesions}

Parietal lesions had restricted effects on the P3. Ipsilateral shock P3, ipsilateral and contralateral target P3, and tactile novelty P3 amplitudes were normal. Thus, substantial portions of lateral parietal cortex do not appear to be necessary for P3 generation. Parictal patients showed P3 amplitude reduction only to contralateral shock stimuli. Dissociation between tactile and shock novelty P3 may be attributed to difference in the stimulus submodality (i.e., tactile and electric shock) because both stimuli had no primary task relevance. It is known that both tactile and electric stimulation excite the same type of peripheral nerve fibers, but that electric stimulation elicits larger primary cortical response in comparison with tactile stimuli (Pratt and Starr, 1981). However, the neural responses to various types of stimuli in the secondary or higher somatosensory cortex have not been examined in humans. The present results suggest that tactile and shock stimulation may be differentially processed in the lateral parietal cortex before being output to the temporal-parietal junction.

Behaviorally, the parietal group had minimal deficits in target detection, with delayed RTs in the order of $100 \mathrm{msec}$. These changes were not different from those seen in the other patient groups. Thus, the tactile target detection task employed in the present study does not seem to be selectively affected by unilateral parietal lesions. In monkeys, tactile discrimination was severely impaired by bilateral ablation of SII or area $7 \mathrm{~b}$ but unilateral ablation did not result in consistent impairment (Garcha and Ettlinger, 1978; LaMotte and Mountcastle, 1979; Murray and Mishkin, 1984). Primary sensation was also preserved in the parietal patients. This result is consistent with Corkin's and Pause and co-workers' clinical observation that somatosensory functions such as pressure sensitivity, two-point discrimination, point localization, and position sense were preserved in the patients with extended unilateral parietal cortical removals sparing postcentral gyrus (Corkin and Milner, 1970; Pause et al., 1989). This contrasts with the severe deficits observed in postcentral gyrus-lesioned patients. 


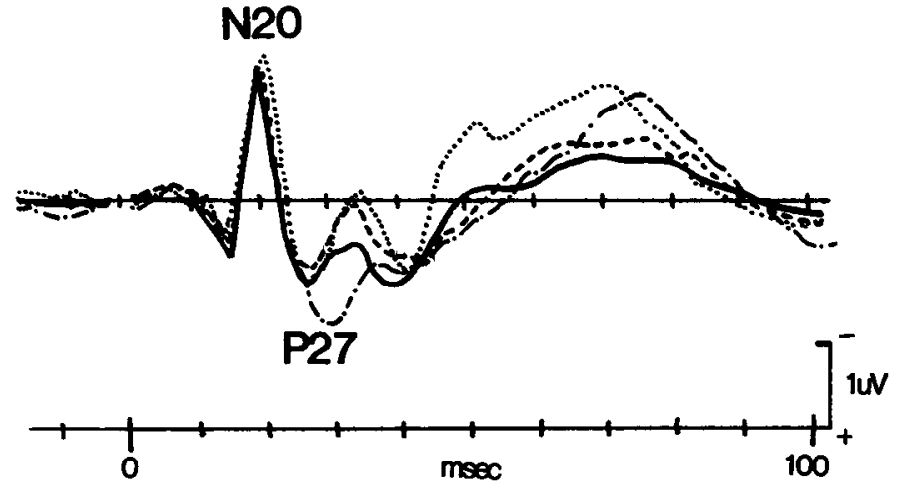

CONTROL PARIETAL

TEMP - PAR - - -

FRONTAL -.-.-..-..-

Figure 10. Grand average SEPs for the three patient groups and controls (sum of 500 stimuli; $3-\mathrm{Hz}$ stimulation; wrist shock). TEMP-PAR, temporal-parietal groups.

Conversely, several higher-order symptoms have been described in posterior parietal lesions (e.g., Brodmann's areas 7, 39, and 40; Critchley, 1953; Denny-Brown and Chambers, 1958). Similar deficits in the analysis of the spatial relationships of somesthetic and visual stimuli, and difficulty in manual construction and somesthetic recognition of objects, were observed in $71 \%$ of our parietal patients.

\section{Frontal lesions}

Frontal patients had reduced tactile and shock novelty P3 amplitude for both contralateral and ipsilateral stimulation, while target P3 amplitude was mildly reduced only for contralateral stimulation. None of these reductions were as severe as those observed in the temporal-parietal junction group. The dissociative effects of dorsolateral frontal cortical lesion on target and novelty P3 suggest that the frontal cortex provides differential contribution to these two types of P3. Similar effects were observed in auditory and visual P3 studies of frontal patients (Knight, 1984, in press; Scabini et al., 1989).

The novelty P3 is related to the momentary shift of attention toward an unexpected perturbation in the environment (Ford et al., 1976; Näätänen and Gaillard, 1983). Thus, the novelty P3 deficits in frontal patients support a relative abnormality in automatic attention capacity in this group. Similar deficits in frontal patients have been demonstrated by other electrophysiological measures (Kimble et al., 1965; Luria and Homskaya, 1970).

Frontal patients had decreased target detection accuracy and prolonged KTs for both contralateral and ipsilateral stimuli in the present study. This result contrasts with studies reporting that frontal patients pcrform normally on simple discrimination tasks (Teuber, 1964, Benson and Stuss, 1982). No such impairments were observed in auditory or visual P3 studies in similar patients (Scabini et al., 1989; Knight, in press).

The somatosensory task employed in the present study requires a precise internal representation of the body schema. Subregions of frontal cortex are proposed to be involved in the processing of representational information about object location in the personal or extrapersonal space (Semmes et al., 1963; Rizzolati et al., 1983; Goldman-Rakic, 1987). Failure to manipulate accurately the representation of the body schema may lead to difficulty in accurate and quick discrimination of stimuli delivered to a part of one's own body and could contribute to the behavioral effects in the present study.

P3 amplitude was more reduced over frontal electrode sites in frontal patients, supporting the hypothesis that part of the scalp P3 may be generated in dorsolateral frontal cortex (Knight, 1984; Wood and McCarthy, 1985). The symmetrical reduction of the novelty P3 by unilateral lesion may be related to the dense transcallosal connections between prefrontal regions (Schwartz and Goldman-Rakic, 1984). Alternatively, dorsolateral frontal cortex could modulate remote $\mathrm{P} 3$ generators, resulting in a change of dipole orientation producing alterations in scalp topography.

\section{N2 component}

Double dissociations between the N2 and P3 components were observed. The $\mathrm{N} 2$ was reduced and the P3 was preserved in some conditions in the parietal group. Conversely, the P3 was abolished and the N2 was preserved for certain conditions in the temporal-parietal group. Because most of the lesioned area in the parietal group was also damaged in the temporal-parietal group, the reason for these dissociations is not apparent. It is conceivable that the "normal N2" in the temporal-parietal group might in part be due to a loss of the P3 component whose onset normally overlaps the $\mathrm{N} 2$ component.

The reduction of the N2 response in the frontal and parietal groups with the intact posterior $\mathrm{P} 3$ response to correctly detected targets argues against the notion that the discriminative processing reflected in the $\mathrm{N} 2$ is critical for P3 generation (Hillyard and Picton, 1987) and indicates that the N2 and P3 are generated by different neural processes.

\section{References}

Allison T, McCarthy G, Wood CC, Darcey TM, Spencer DD, Williamson PD (1989) Human cortical potentials evoked by stimulation of the median nerve. I. Cytoarchitectonic areas generating short-latency activity. J Neurophysiol 62:694-710.

Amaral DG, Insausti R, Cowan WM (1983) Evidence for a direct projection from the superior temporal gyrus to the entorhinal cortex in the monkey. Brain Res 275:263-277.

Andersen RA, Asanuma C, Cowan WM (1985) Callosal and prefrontal associational projecting cell populations in area $7 \mathrm{a}$ of the macaque monkey: a study using retrogradely transported fluorescent dyes. J Comp Neurol 232:443-455.

Beck EC, Swanson C, Dustman RE (1980) Long latency components of the visual evoked potentials in man: effects of aging. Exp Aging Res 6:523-545.

Benson DF, Stuss DT (1982) Motor abilities after frontal leukotomy. Neurology 32:1353-1357.

Corkin S, Milner B (1970) Somatosensory thresholds: contrasting effects of postcentral-gyrus and posterior parietal-lobe excisions. Arch Neurol 23:41-58.

Courchesne E, Hillyard SA, Galambos R (1975) Stimulus novelty, task relevance, and the visual evoked potential in man. Electroencephalogr Clin Neurophysiol 39:131-143.

Critchley M (1953) The parietal lobes. London: Arnold.

Denny-Brown D, Chambers RA (1958) The parietal lobe and behavior. Res Nerv Ment Dis Proc 36:35-117.

Desmedt JE, Debecker J, Manil J (1965) Mise en evidence d'un signe electrique cerebral associe a la detection par le sujet d'un stimulus sensoriel tactile. Bull Acad R Med Belgique 5:887-936.

Desmedt JE, Debecker J, Robertson D (1979) Serial perceptual processing and the neural basis of changes in event-related potential 
components and slow potential shifts. Prog Clin Neurophysiol 6:5379.

Donchin E (1979) Event-related potentials: a tool in the study of human information processing. In: Evoked brain potentials and behavior, Vol 2 (Begleiter H, ed), pp 13-88. New York: Plenum.

Fabiani M, Karis D, Donchin E (1986) P300 and recall in an incidental memory paradigm. Psychophysiology 23:298-308.

Ford JM, Roth WT, Kopell BS (1976) Auditory evoked potentials to unpredictable shifts in pitch. Psychophysiology 13:32-39.

Garcha HS, Ettlinger G (1978) The effects of unilateral or bilateral removals of the second somatosensory cortex (area SII): a profound tactile disorder in monkeys. Cortex 14:319-326.

Goldman-Rakic PS (1987) Circuitry of primate prefrontal cortex and regulation of behavior by representational memory. In: Handbook of physiology, the nervous system, Vol 5, Higher function of the brain, pt 1, pp 373-417, New York: Oxford UP.

Goldman-Rakic PS, Schwartz ML (1982) Integration of contralateral and ipsilatcral columnar projections to frontal association cortcx in primates. Science 216:755-757.

Halgren E, Squires NK, Wilson CL, Rohrbaugh JW, Babb TL, Crandall PH (1980) Endogenous potentials generated in the human hippocampal formation by infrequent events. Science 210:803-805.

Harrison JB, Buchwald JS, Kaga K, Woolf NJ, Butcher LL (1988) "Cat P300" disappears after septal lesions. Electroencephalogr Clin Neurophysiol 69:55-64.

Heilman KM, Watson RT, Valenstein E, Goldberg ME (1987) Attention: behavior and neural mechanisms. In: Handbook of physiology, the nervous system, Vol 5, Higher function of the brain, Pt 1, pp 461481. New York: Oxford UP

Hikosaka K, Iwai E, Saito H, Tanaka K (1988) Polyresponse properties of neurons in the anterior bank of the caudal superior temporal sulcus of the macaque monkey. J Neurophysiol 60:1615-1637.

Hillyard SA, Picton TW (1987) Electrophysiology of cognition. In: Handbook of physiology, the nervous system, Vol 5, Higher function of the brain, Pt 2, pp 519-584. New York: Oxford UP.

Johnson R (1988) Scalp-recorded P300 activity in patients following unilateral temporal lobectomy. Brain 111:1517-1529.

Katayama Y, Tsukiyama T, Tsubokawa T (1985) Thalamic negativity associated with the endogenous late positivity component of cerebral evoked potentials ( $\mathrm{P} 3$ ): recordings using discriminative aversive conditioning in humans and cats. Brain Res Bull 14:223-226.

Kersteen-Tucker Z, Knight RT (1989) Cortical lesions dissociate short and long term components of repetition priming. Soc Neurosci Abstr 15:245.

Kimble DP, Bagshaw MH, Pribram KH (1965) The GSR of monkeys during orienting and habituation after selective partial ablations of the cingulate and frontal cortex. Neuropsychologia 3:121-128.

Knight RT (1984) Decreased response to novel stimuli after prefrontal lesions in man. Electroencephalogr Clin Neurophysiol 59:9-20.

Knight RT (1990) ERPs in patients with focal brain lesions. Electroencephalogr Clin Neurophysiol 75:S72.

Knight RT (in press) Evoked potential studies of attention capacity in human frontal lobe lesions. In: Frontal lobe function and dysfunction (Levin $\mathrm{H}$, Eisenberg $\mathrm{H}$, Benton $\mathrm{F}$, eds). London: Oxford UP, in press.

Knight RT, Scabini D, Woods DL, Clayworth CC (1989) Contribution of temporal-parietal junction to the human auditory P3. Brain Res 502:109-116.

Kutas M, Hillyard SA, Volpe BT, Gazzaniga MS (1990) Late positive event-related potentials after commissural section in humans. J Cogn Neurosci 2:258-271.

LaMotte RH, Mountcastle VB (1979) Disorders in somesthesis following lesions of parietal lobe. J Neurophysiol 42:400-419.

Luria AR, Homskaya ED (1970) Frontal lobes and the regulation of arousal process. In: Attention: contemporary theory and analysis (Mostofsky DI, ed), pp 303-330. New York: Appleton-Century-Crofts.

McCarthy G, Wood CC, Williamson PD, Spencer DD (1989) Taskdependent field potentials in human hippocampal formation. J Neurosci 9:4253-4268.

Mesulam MM (1983) The functional anatomy and hemispheric specialization for directed attention. Trends Neurosci 6:384-387.

Mesulam MM, Van Hoesen GW, Pandya DN, Geschwind N (1977) Limbic and sensory connections of the inferior parietal lobule (area PG) in the rhesus monkey: a study with a new method for HRP histochemistry. Brain Res 136:393-414.
Murray EA, Mishkin M (1984) Relative contributions of SII and area 5 to tactile discrimination in monkeys. Behav Brain Res 11:67-83.

Näätänen R, Gaillard AWK (1983) The orienting reflex and the N2 deflection of the event-related potential (ERP). In: Tutorials in eventrelated potentials research: endogenous component (Gaillard AWK, Ritter W, eds), pp 119-141. Amsterdam: Elsevier.

Neville HJ, Kutas M, Chesney G, Schmidt A (1986) Event-related brain potentials during initial encoding and subsequent recognition memory of congruous and incongruous words. J Mem Lang 25:7592.

Okada YC, Kaufman L, Williamson SJ (1983) The hippocampal formation as a source of the slow endogenous potentials. Electroencephalogr Clin Neurophysiol 55:417-426.

Paller KA, Kutas M, Shimamura AP, Squire LR (1987) Brain responses to concrete and abstract words reflect processes that correlate with later performance on a test of stem-completion priming. In: Current trends in event-related potential research (Johnson $\mathrm{R} \mathrm{Jr}$, Rohrbaugh JW, Parasuraman R, cds), pp 360-365. Amsterdam: Elsevier.

Paller KA, Zola-Morgan S, Squire LR, Hillyard SA (1988) P3-like brain wave in normal monkeys and in monkeys with medial temporal lesions. Behav Neurosci 102:714-725.

Pause M, Kunesch E, Binkofski F, Freund H-J (1989) Sensorimotor disturbances in patients with lesions of the parietal cortex. Brain 112: $1599-1625$

Pineda JA, Foote SL, Neville HL (1989) Effect of locus coeruleus lesion in auditory, long-latency, event-related potentials in monkey. J Neurosci 9:81-93.

Pratt H, Starr A (1981) Mechanically and electrically evoked somatosensory potentials in humans: scalp and neck distributions of short latency components. Electroencephalogr Clin Neurophysiol 49:240 249.

Rizzolatti G, Matelli M, Pavesi G (1983) Deficits in attention and movement following the removal of postarcuate (area 6) and prearcuate (area 8) cortex in macaque monkeys. Brain 106:655-673.

Scabini D, Knight RT, Woods DL (1989) Frontal lobe contributions to the human P3a. Soc Neurosci Abstr 15:477.

Scherg M, Von Cramon D (1986) Evoked dipole source potentials of the human auditory cortex. Electroencephalogr Clin Neurophysiol 65: 344-360.

Schwartz ML, Goldman-Rakic PS (1984) Callosal and intrahemispheric connectivity of the prefrontal association cortex in rhesus monkey: relation between intraparietal and principal sulcal cortex. $J$ Comp Neurol 226:403-420.

Seltzer B, Murphy T (1989) Contralateral cortical projections of the superior temporal sulcus in the rhesus monkey. Soc Neurosci Abstr 15:73.

Semmes J, Weinstein S, Ghent L, Teuber HL (1963) Correlates of impaired orientation in personal and extrapersonal space. Brain 86: 747-772.

Smith ME, Halgren E, Sokolik M, Baudeua P, Musolino A, Chauvel CL, Chauvel P (1990) The intracranial topography of the P3 eventrelated potential elicited during auditory oddball. Electroencephalogr Clin Neurophysiol 76:235-248.

Squires NK, Squires KC, Hillyard SA (1975) Two variables of longlatency positive waves evoked by unpredictable auditory stimuli in man. Electroencephalogr Clin Neurophysiol 38:387-401.

Stapleton JM, Halgren E, Moreno KA (1987) Endogenous potentials after anterior temporal lobectomy. Neuropsychologia 25:549-557.

Sutherling WW, Crandall PH, Darcey TM, Becker DP, Levesque MF, Barth DS (1988) The magnetic and electric fields agree with intracranial localizations of somatosensory cortex. Neurology 38:17051714.

Sutton S, Braren M, Zubin J, John ER (1965) Evoked potentials correlates of stimulus uncertainty. Science 150:1187-1188.

Teuber HL (1964) The riddle of frontal lobe function in man. In: The frontal granular cortex and behavior (Warren JM, Akert K, eds), pp 410-444. New York: McGraw-Hill.

Tulving E, Schacter DL (1990) Priming and human memory systems. Science 247:301-306.

Vaughan HG Jr, Ritter W, Simpson R (1983) Neurophysiological considerations in event-related potential research. In: Tutorials in event-related potential research: endogenous components (Gaillard WK, Ritter W, eds), pp 1-7. Amsterdam: Elsevier. 
Velasco M, Velasco F, Velasco AL, Almanza X, Olivera A (1986) Subcortical correlates of the P300 potential complex in man to auditory stimuli. Electroencephalogr Clin Neurophysiol 64:199-210.

Wood CC, McCarthy G (1985) A possible frontal lobe contribution to scalp P3. Soc Neurosci Abstr 11:879.

Wood CC, Allison T, Goff WR, Williamson PD, Spencer DD (1980) On the neural origin of P300 in man. In: Progress in brain research, Vol 54, Motivation, motor, and sensory processes of the brain: electrical potentials, behavior and clinical use (Kornhuber $\mathrm{HH}$, Deecke L, eds), pp 51-56. Amsterdam: Elsevier.
Wood CC, McCarthy G, Allison T, Goff WR, Williamson PD, Spencer DD (1982) Endogenous event-related potentials following temporal lobe excisions in humans. Soc Neurosci Abstr 8:976.

Yamaguchi S, Knight RT (1990) Gating of somatosensory input by human prefrontal cortex. Brain Res 521:281-288.

Yamaguchi S, Knight RT (1991) P300 generation by novel somatosensory stimuli. Electroencephalogr Clin Neurophysiol 78:50-55.

Yingling CD, Hosobuchi Y (1984) A subcortical correlate of P3 in man. Electroencephalogr Clin Neurophysiol 59:72-76. 